\title{
Success and Failure Rates of Orthodontic Microimplants (A clinical Study)
}

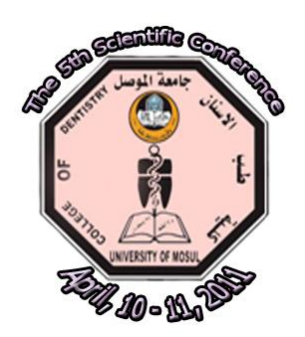

\begin{abstract}
Aims: To evaluate the rates of success and failure regarding the mobility of orthodontic microimplants in patients undergoing fixed orthodontic appliance treatment. Materials and Methods: The sample consisted of 36 titanium microimplants (AbsoAnchor ${ }^{\circledR}$, Dentos inc. Korea) inserted in 15 female patients. The mean age for the patients was 25.53 years. Microimplants of $1.2 \mathrm{~mm}$ in diameter and $6-10 \mathrm{~mm}$ in length were used. A self-drilling method was used. A small vertical stab incision and the microimplants inserted with a screwdriver. The patients were seen periodically every 3-4 weeks. A microimplant with complete absence of a clinically detectable mobility was considered as a successful one. Whereas failure was defined as a microimplant mobility within 8 months. Results and Discussion: The total success rate for microimplants for both jaws was $(86.1 \%)$. Whereas a $(91.7 \%)$ success rate was recorded in the upper jaw and in the lower jaw it was (75\%).Despite of higher failure rates in the mandible, which may be attributed to the occlusal force, yet they remain non significantly different from those in maxilla. Conclusions: The relatively high success rates of microimplants make them an appropriate solution for providing absolute anchorage whenever being needed in orthodontic therapy.
\end{abstract}

Lect Ahmad A Abdulmawjood (BDS, MSc); Lect Mahmood Kh Ahmad (BDS, MSc); Asst lect Zaid S Tawfiq (BDS, MSc)

Department of Pedodontics, Orthodontics and Preventive Dentistry, Dentistry College, Mosul University

Key words: Microimplant, orthodontic miniscrew, absolute anchorage.

$2 \%$ nchorage control in edgewise treatment is an important factor affecting treatment results. In the traditional approach, appliances such as headgear and intraoral elastics are used to reinforce anchorage, but it is difficult to obtain stationary anchorage even when the patients show excellent cooperation. ${ }^{(1,2)}$ The need for orthodontic treatment requiring minimal patient compliance has encouraged research into the use of implants as tools to reinforce anchorage. More recently, smaller implants were introduced as temporary skeletal anchorage devices. ${ }^{(3)}$

Achieving absolute anchorage has been one of the dreams of the practicing orthodontist, and microimplants have become one of the most effective and powerful tools for achieving absolute anchorage. ${ }^{(4)}$

The orthodontic microimplant is temporarily fixed to the bone to accomplish difficult tooth movement. In certain cases, the micro-implant can reduce treatment time, simplify orthodontic treatment, improve results or provide an alternative to surgical correction. The use of microimplants has broad clinical application including retraction of teeth, protraction of the posterior teeth, molar uprighting, molar distalizing, midline correction, intrusion of anterior and posterior teeth, and correction of occlusal canting. ${ }^{(4)}$ 
Microimplants are small in size, simple in implantation and removal can be fully loaded early or immediately after placement, and are removed at the end of treatment. They are easy to insert, safe, cause little or no discomfort, and are simple to remove. ${ }^{(2,5)}$

Recently, and because of the rigid stability of microimplants in bone and independency of patient compliance, ${ }^{(5)}$ there has been a dramatic increase in the use of orthodontic microimplant(1.2 to $1.3 \mathrm{~mm}$ in diameter) due, in part, to the fact that they can be placed between the roots of adjacent teeth, provide absolute anchorage, decrease the need for patient cooperation, and further simplify the treatment procedure. ${ }^{(1,4)}$

The present study tries to investigate the success and failure rates of microimplants (AbsoAnchor ${ }^{\circledR}$, Dentos inc. Korea) placed in patients undergoing orthodontic treatment with fixed appliances.

\section{MATERIALS AND METHODS}

The sample consisted of 36 titanium microimplants (AbsoAnchor ${ }^{\circledR}$, Dentos inc. Korea) inserted in 15 female patients undergoing fixed orthodontic appliance treatment. The mean age for the patients was 25.53 years. The microimplants used in the study were $1.2 \mathrm{~mm}$ in diameter and range from $6-10 \mathrm{~mm}$ in length. Twenty four microimplants were inserted in the upper jaw in the interdental space between first molar and second premolar except one which was placed between upper two central incisors. While in the lower jaw 12 microimplants were inserted, interdentally, between first molar and second premolar.

A periapical radiograph was taken for each site that would receive a microimplant to evaluate the amount of bone available and to ensure that there is adequate space to insert microimplants without damaging the tooth root or other anatomic structures, such as nasal and sinus cavities and neurovascular bundles. ${ }^{(6,7)}$

A self drilling (drilling free) method was used in this study were the microimplant act as a drill as it is being inserted into the bone. The surgical procedure included local anesthesia, a small vertical stab incision $(3-5 \mathrm{~mm})$, and placement of the microimplants with a screwdriver (Figure 1). The incision is necessary to prevent the soft tissue from rolling up around the microimplants. $^{(4,8-11)}$ Special care was taken to insert the microimplants as deep as possible so that the head of the microimplants touched the soft tissue and no part of the thread was visible after terminating the insertion. ${ }^{(12)}$

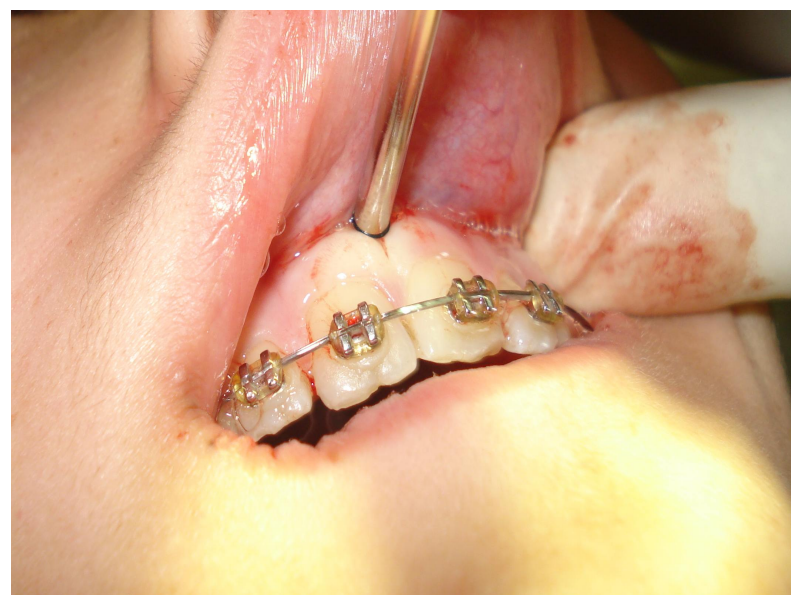

Figure (1): Insertion of the microimplants with a screwdriver. 
The microimplants in the maxilla were inserted, in the Interradicular area, ${ }^{(13)} 30-60$ degrees of angulation to the long axis of the teeth in order to augment the surface area contact between the microimplant and the cortical bone and also increases retention while lowering the risk of making contact with a root. ${ }^{(8,14)}$ If the patient felt some sensitivity during microimplant driving, that sensation is a sign of the microimplant touching the roots, the microimplant was redirected away from them. ${ }^{(15)}$ While in the mandible, having a thicker cortex, the microimplant was usually inserted more perpendicular to the long axis of the teeth. ${ }^{(14)}$ Just after insertion, the initial stability was checked ensuring no sign of mobility. ${ }^{(8)}$

After placement of the microimplant, another periapical radiograph was taken to evaluate the distance between the microimplant and the root. ${ }^{(16)}$ The patients were instructed to maintain adequate oral hygiene, taking care not clean the head of the microimplant excessively. They were also told to avoid manipulating the head of the microimplant with their fingers, tongue, lip or check. ${ }^{(17)}$

An orthodontic force less than 200 grams was applied to the microimplant from 2-3 weeks after placement using elastic chains (Figure 2). ${ }^{(18)}$ The patients were seen periodically every 3-4 weeks. ${ }^{(12)}$ Mobility was checked with cotton tweezers, ${ }^{(8,19)}$ the complete absence of clinically detectable mobility, of a microimplant, and capability of sustaining the anchorage function throughout the course of orthodontic treatment (more than 8 months or until completion of treatment purposes) ${ }^{(7,20)}$ was considered as a successful one. Where as failure was defined as microimplant mobility or microimplant loss in less than 8 months or before completion of treatment. $^{(20,21)}$

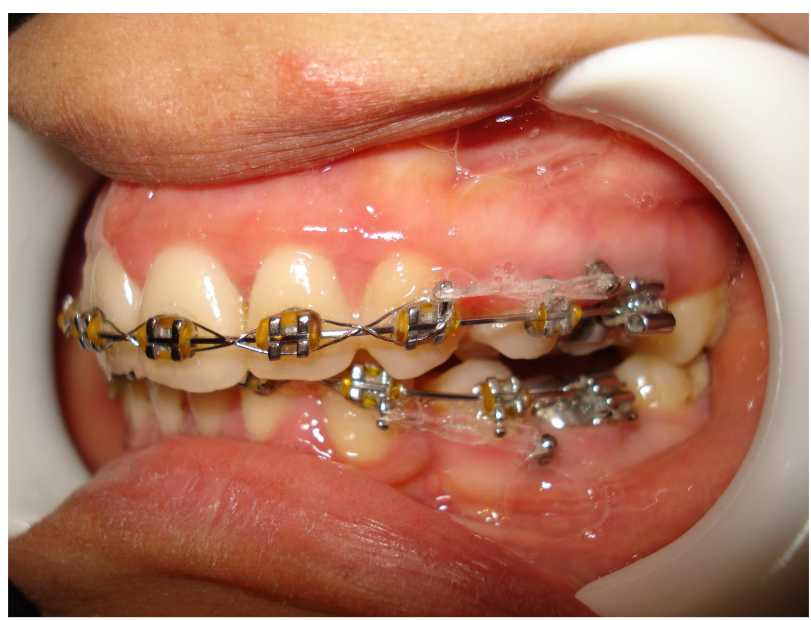

Figure (2): Elastic chains traction from the microimplant.

\section{RESULTS}

Five microimplants out of the total number (36) microimplants were failed during the first three months after placement. The overall success rate was $86.1 \%$ (overall failure $13.9 \%, \mathrm{n}=$ 5). In the maxilla the success rate was $91.7 \%$ and the failure rate was $8.3(\mathrm{n}=2)$, whereas in the lower jaw the success rate was $75 \%$ while the failure was $25 \%(n=3)$. These results are shown in Table (1). 
Table (1): Descriptive analysis involved means, standard deviations and percentage of frequency for the scores of success and failure for total, upper and lower jaws.

\begin{tabular}{cccccccc}
\hline Jaw & \multirow{2}{*}{$\mathbf{N}$} & Minimum & Maximum & Mean & $\mathbf{\pm}$ SD & \multicolumn{2}{c}{ Scores (Percentage of Frequency) } \\
\hline Upper & 24 & 1.00 & 2.00 & 1.083 & 0.28 & $91.7 \%$ & $\mathbf{2}$ \\
Lower & 12 & 1.00 & 2.00 & 1.25 & 0.45 & $75 \%$ & $8.3 \%$ \\
\hline Total & 36 & 1.00 & 2.00 & 1.13 & 0.35 & $86.1 \%$ & $13.9 \%$ \\
\hline
\end{tabular}

*1: success

$* * 2$ : failure

Statistical analysis using Mann-Whitney Test revealed no significant differences in success/failure rates of microimplants between upper and lower jaws as shown in Table (2).

Table (2): Comparison between means scores of upper and lower jaws.

\begin{tabular}{ccc}
\hline CLASS & $\mathbf{N}$ & Z-Value \\
\hline Upper & 24 & $-1.34^{*}$ \\
\hline Lower & 12 & \\
\hline
\end{tabular}

* non significant difference at $p \leq 0.05$.

\section{DISCUSSION}

The failure of an orthodontic microimplant usually means that the microimplant becomes loose during treatment which usually occurs during the first three months. The success rate of microimplants used for temporary anchorage varies from study to study in the literature. Currently a $100 \%$ success for microimplant placement is not attainable. ${ }^{(4)}$

Approximately $10 \%$ of orthodontic mini-implants fail. This rate is slightly higher than that for dental implants and can be attributed to the fact that the orthodontic mini-implant is not designed to osseointegrate. Osseointegration would complicate implant removal and is therefore not desired. ${ }^{(8)}$

The current study showed a total success rate of $86.1 \%$ and $91.7 \%$ and $75 \%$ in the upper and lower jaws respectively. In this study, the failure rates were higher in the mandible even though it has denser and thicker cortical bone than in the maxilla. This failure may be attributed to the occlusal force applied to buccal mandibular microimplants. ${ }^{(22)}$ These results are similar to those of Woo et al. ${ }^{(23)}$ and Berens et al. ${ }^{(12)}$ who also reported higher failure rate percentages in the lower jaw.

Park et al. ${ }^{(9)}$ reached similar results for total success rate of microimplants of $91.9 \%, 96$ $\%$ in the maxilla and $86.4 \%$ in the mandible. Whereas Park ${ }^{(11)}$ reported a higher total success rate $(93.3 \%)$ than the current study, he also, unlikely showed a higher failure rate in the maxilla compared with the mandible.

\section{CONCLUSIONS}

Despite of some failures of microimplants, the major advantage of providing absolute anchorage without patient cooperation make them suitable means and an excellent substitute of achieving such an anchorage whenever needed. 


\section{REFERENCES}

1. Kuroda S, Sugawara Y, Deguchi T, Kyung HM, Takano-Yamamoto T. Clinical use of miniscrew implants as orthodontic anchorage: Success rates and postoperative discomfort. Am J Orthod Dentofacial Orthop. 2007; 131: 9-15.

2. Miyawaki S, Koyama I, Inoue M, Mishima K, Sugahara T, Takano-Yamamoto T. Factors associated with the stability of titanium screws placed in the posterior region for orthodontic anchorage . Am J Orthod Dentofacial Orthop. 2003; 124: 373-8

3. Cornelis MA, Scheffler NR, De Clerck HJ, Tulloch JFC, Nyssen-Behets C. Systematic review of the experimental use of temporary skeletal anchorage devices in orthodontics. Am J Orthod Dentofacial Orthop. 2007;131.

4. Sung JH, Kyung HM, Bae SM, Park HS, Kwon OH, McNamara JA Jr. Microimplant in orthodontic. $1^{\text {st }}$ ed. Dentos, Inc. 2006. Pp: 165, 173.

5. Deguchi T, Takano-Yamamoto T, Kanomi R, Hartsfield JK Jr, Roberts WE, Garetto LP. The Use of Small Titanium Screws for Orthodontic Anchorage. J Dent Res. 2003; 82(5):377-381.

6. McGuire MK, Scheyer ET, Gallerano RL. Temporary anchorage devices for tooth movement: A review and case reports. J Periodontol. 2006; 77(10): 1613-24.

7. Luzi C, Verna C, Melsen B. A prospective clinical investigation of the failure rate of immediately loadedminiimplants used for orthodontic anchorage. Orthod. 2007; 8(1): 192-201.

8. Park HS, Jeong SH, Kwon OW. Factors affecting the clinical success of screw implants used as orthodontic anchorage. Am J Orthod Dentofacial Orthop. 2006; 130: 18-25.

9. Arturo F, Vittorio C, Francesca SM, Stefano C, Massimo L. Clinical applications and efficiency of miniscrews for extradental Anchorage. Orthod. 2004; 1(2): 1-11.

10. Zhang L, Zhao Z, Li Y, Wu J, Zheng L, Tang T. Osseointegration of orthodontic micro-screws after immediate and early loading. Angle Orthod. 2010; 80: 354-360.

11. Park HS. Clinical study on success rate of microscrew implants for orthodontic anchorage. Korea J orthod. 2003; 33(3): 151-56.

12.BerensA,Wiechmann D, Rüdiger J. Skeletal anchorage in orthodontics with mini- and microscrews. Inf Orthod Kieferorthop. 2005; 37: 283-287.

13. Liu H, Lv T, Wang N, Zhao F, Wang K, Liud D. Drift characteristics of miniscrews and molars for anchorage under orthodontic force: 3-dimensional computed tomography registration evaluation. Am J Orthod Dentofacial Orthop. 2011; 139: e83-e89.

14. Kyung HM, Park HS, Bae SM, Kwon OH, Sung JH. Brochure for the AbsoAnchor® Orthodontic Microimplant. $6^{\text {th }}$ ed. 2008 .

15. Kyung HM, Park HS, Bae SM, Kwon OH, Sung JH. Brochure for the AbsoAnchor® Orthodontic Microimplant. $4^{\text {th }}$ ed. 2006.

16. Kuroda S, Yamada K, Deguchi T, HashimotoT, Kyung HM, Takano-Yamamoto T. Root proximity is a major factor for screw failure in orthodontic anchorage. Am J Orthod Dentofacial Orthop. 2007; 131.

17. Tsaousidis G, Bauss O. Influence of insertion site on the failure rates of orthodontic miniscrews. J Orofac Orthop. 2008; 69: 349-56.

18.Moon CH, Lee DG, Lee HS, Im JS, Baek SH. Factors associated with the success rate of orthodontic miniscrews placed in the upper and lower posterior buccal region. Angle Orthod. 2008; 78(1): 101-106.

19. Y Chen Y, Kang ST, Bae SM, Kyung HM. Clinical and histologic analysis of the stability of microimplants with immediate orthodontic loading in dogs. Am J Orthod Dentofacial Orthop. 2009; 136: 260-7.

20. Takaki T, Tamura N, Yamamoto M, Takano N, Shibahara T, Yasumura T, Nishii Y, Sueishi K. Clinical study of temporary anchorage devices for orthodontic treatment- Stability of micro/mini-screws and mini-plates: Experience with 455cases. Bull Tokyo Dent Coll. 2010; 51(3): 151-163.

21. Baek SH, Kim BM, Kyung SH, Lim JK, Kim YH. Success rate and risk factors associated with mini-implants reinstalled in the Mmaxilla. Angle Orthod. 2008; 78(5): 895-901.

22. An Informal JCO Survey. Factors contributing to the Success or Failure of Skeletal Anchorage Devices. $J$ clin orthod. 2010; 44(12): 714-718.

23. Woo SS, Jeong ST, Huh YS, Hwang KG. A clinical study on skeletal anchorage system using miniscrew. $J$ Korean oral maxillofascial surg. 2003; 29(2): 102-107. 